\title{
Effect of a high-fat-high-fructose diet, stress and cinnamon on central expression of genes related to immune system, hypothalamic-pituitary- adrenocortical axis function and cerebral plasticity in rats
}

\author{
Nathalie Marissal-Arvy ${ }^{1,2 *}$, Cécile Batandier ${ }^{3}$, Julien Dallennes ${ }^{1,2}$, Frédéric Canini ${ }^{4,5}$, Laurent Poulet ${ }^{4,5}$, \\ Karine Couturier ${ }^{3}$, Isabelle Hininger-Favier ${ }^{3}$, Marie-Pierre Moisan ${ }^{1,2}$, Anne-Marie Roussel ${ }^{3}$ and \\ Pierre Mormède ${ }^{1,2} \dagger$ \\ ${ }^{1}$ INRA, Laboratory of Nutrition and Integrative Neurobiology, UMR 1286, Pharmacy Building 2nd Floor, 33076 Bordeaux \\ Cedex, France \\ ${ }^{2}$ University of Bordeaux, Laboratory of Nutrition and Integrative Neurobiology, UMR 1286, 33076 Bordeaux Cedex, France \\ ${ }^{3}$ LBFA/INSERM, U1055, BP 53X, 38041 Grenoble Cedex, France \\ ${ }^{4}$ IRBA-CRSSA, Unité de Neurophysiologie du stress, 38702 La Tronche Cedex, France \\ ${ }^{5}$ Ecole du Val de Grâce, 1 place Laveran, 75005 Paris, France
}

(Submitted 4 December 2012 - Final revision received 10 September 2013 - Accepted 11 September 2013 - First published online 20 November 2013)

\begin{abstract}
The intake of a high-fat/high-fructose ( $\mathrm{HF} / \mathrm{HFr}$ ) diet is described to be deleterious to cognitive performances, possibly via the induction of inflammatory factors. An excess of glucocorticoids is also known to exert negative effects on cerebral plasticity. In the present study, we assessed the effects of an unbalanced diet on circulating and central markers of inflammation and glucocorticoid activity, as well as their reversal by dietary cinnamon $(\mathrm{CN})$ supplementation. A group of male Wistar rats were subjected to an immune challenge with acute lipopolysaccharide under a HF/HFr or a standard diet. Another group of Wistar rats were fed either a HF/HFr or a control diet for 12 weeks, with or without $\mathrm{CN}$ supplementation, and with or without restraint stress (Str) application before being killed. We evaluated the effects of such regimens on inflammation parameters in the periphery and brain and on the expression of actors of brain plasticity. To assess hypothalamic-pituitary-adrenocortical axis activity, we measured the plasma concentrations of corticosterone and the expression of central corticotrophin-releasing hormone, mineralocorticoid receptor, glucocorticoid receptor and 11 $\beta$-hydroxysteroid dehydrogenase. We found that the HF/HFr diet induced the expression of cytokines in the brain, but only after an immune challenge. Furthermore, we observed the negative effects of Str on the plasma concentrations of corticosterone and neuroplasticity markers in rats fed the control diet but not in those fed the HF/HFr diet. Additionally, we found that CN supplementation exerted beneficial effects under the control diet, but that its effects were blunted or even reversed under the HF/HFr diet. CN supplementation could be beneficial under a standard diet, but deleterious under the unbalanced diet encountered in Western societies.
\end{abstract}

Key words: High-fat diets: Inflammation: Neurogenesis: Synaptogenesis

Nutritional overload of fat and refined carbohydrates contributes to the development of obesity and insulin resistance. Other medical consequences can be associated with visceral obesity, such as $\mathrm{CVD}^{(1)}$, type 2 diabetes ${ }^{(2)}$, cancer $^{(3)}$ and cognitive deficiencies $^{(4,5)}$, making its prevalence in Western countries a serious public health concern. The association of these diseases with obesity is well documented, but the biological connection between them is still under debate. The major experimental studies focusing on the association between diets and these diseases have been carried out using high-fat diets. However, during the last decade, public health campaigns have led to a decline in the intake of fat and there has been an increase in the intake of fructose. This increase in the intake of refined sugars high in fructose appears to be an important factor for the

\footnotetext{
Abbreviations: $11 \beta-H S D, 11 \beta$-hydroxysteroid dehydrogenase; BDNF, brain-derived neurotrophic factor; C, control; CN, cinnamon; DlGap2, discs, large (Drosophila) homolog-associated protein 2; Gp130, glycoprotein 130; GR, glucocorticoid receptor; HF/HFr, high-fat/high-fructose; HPA, hypothalamicpituitary-adrenocortical axis; IL-1R, IL-1 receptor; ITGAM, integrin- $\alpha$ M; LPS, lipopolysaccharide; MR, mineralocorticoid receptor; NGF, nerve growth factor; qPCR, quantitative PCR; Str, stress; SYP, synaptophysin; TGF, transforming growth factor; TNF-R, TNF receptor 1.
}

*Corresponding author: N. Marissal-Arvy, fax +33 557571227, email nathalie.arvy@bordeaux.inra.fr 
development of obesity and the metabolic syndrome in Western countries $^{(6,7)}$. The first objective of the present study was to investigate the impact of a high-fat/high-fructose $(\mathrm{HF} / \mathrm{HFr})$ diet on several biological processes that are suspected to play a role in the development of visceral obesity and related diseases, including the innate immune system and the hypothalamicpituitary-adrenocortical (HPA) axis, in rats.

Some cytokines, TNF- $\alpha$, IL- $1 \beta$ and IL-6, partly secreted by visceral fat, could be involved in the development of insulin resistance ${ }^{(8,9)}$ and of cognitive deficiencies associated with obesity $^{(10)}$. Therefore, we first focused on the components of the innate immune system in the plasma and central structures, hypothalamus and hippocampus, described to respond to immune challenges ${ }^{(11,12)}$ and to be involved in neurogenesis $^{(13,14)}$. We assessed whether a HF/HFr diet modified the system in basal conditions and its response to a lipopolysaccharide (LPS) challenge as classically described ${ }^{(11)}$

A large individual variability in HPA axis function ${ }^{(15)}$, with a high genetic component ${ }^{(16)}$ that influences feeding behaviour, metabolism and energy expenditure ${ }^{(17)}$, has been described. Visceral obesity is usually associated with an overexpression of $11 \beta$-hydroxysteroid dehydrogenase (11 $\beta$-HSD) type 1 in adipose tissue $^{(18)}$, an alteration of the HPA axis negative feedback or a blunted circadian rhythm of corticosterone ${ }^{(19,20)}$. Glucocorticoids are known to induce insulin resistance directly by altering insulin signal transduction and indirectly by promoting visceral fat deposition and lean mass loss. Through both the mineralocorticoid receptor (MR) and glucocorticoid receptor (GR), glucocorticoid hormones stimulate preadipocyte differentiation, contribute to fat accumulation and drive adipose tissue distribution ${ }^{(21,22)}$. The interplay between the HPA axis and metabolic disorders may also be mediated by inflammatory processes, since glucocorticoids modulate the secretion and action and cytokines ${ }^{(23)}$ and cytokines down-regulate the function of $\mathrm{GR}^{(24)}$. Glucocorticoids could also be involved in cognitive deficiencies associated with obesity by their central action, notably in the hypothalamus and hippocampus, as largely described in the literature, for instance, after chronic stress (Str) ${ }^{(16)}$. Therefore, the second objective of the present study was to analyse the effects of a HF/HFr diet on the actors of HPA axis function in basal conditions and in response to acute restraint Str: corticosterone in the plasma and expression of $\mathrm{MR}$, GR, $11 \beta-H S D 1$ and $11 \beta-H S D 2$ in two central structures, hypothalamus and hippocampus, that are both components and targets of the HPA axis.

Some nutritional factors, such as polyphenols, may improve insulin resistance through their insulin-potentiating, antioxidant, anti-inflammatory and related properties. Since the beneficial effects of cinnamon $(\mathrm{CN})$ on inflammation ${ }^{(25)}$ and insulin resistance in humans ${ }^{(26)}$ and on cognitive functions in an Alzheimer's disease animal model ${ }^{(27)}$ have been described, the third objective of the present study was to test whether dietary $\mathrm{CN}$ supplementation could counteract the effects of a HF/HFr diet and/or Str on the inflammation status and HPA axis.

To this end, we measured the effects of a standard $v$. a $\mathrm{HF} / \mathrm{HFr}$ diet, supplemented or not supplemented with $\mathrm{CN}$, coupled or not with restraint Str on plasma cytokines and corticosterone and on hypothalamic and hippocampal expression of immune factors, actors of HPA axis function and actors of cerebral plasticity.

\section{Materials and methods}

\section{Animals}

The present study was approved by the institutional ethics committee for animal care of the Centre de Recherche du Service de Santé des Armées. All the experiments were carried out according to the French (Directive 87/148, Ministère de l'Agriculture et de la Pêche) and international (Directive 86/609, 24 November 1986, European Community) legislation. The procedures followed in the study were approved by Région Aquitaine Veterinary Services (Direction Départementale de la Protection des Animaux, approval ID: A33-063-920). The local ethics committee specifically approved the study. Every effort was made to minimise suffering and the number of animals used. Male Wistar rats (Charles River), 5 weeks old (body weight 194.2 (SE 1.7) g), were used for the study. The rats were individually housed in a temperature-controlled room $\left(22^{\circ} \mathrm{C}\right)$ under a $12 \mathrm{~h}$ light$12 \mathrm{~h}$ dark cycle (lights on at 08.00 hours). At the end of the experiments, in the morning (09.00-12.00 hours), the rats were killed under deep anaesthesia (3-4\% fluothane in $100 \% \mathrm{O}_{2}$ ). Blood samples were collected by cardiac puncture into EDTA-coated tubes (Sarstedt) to avoid haemolysis. Blood samples were centrifuged at $4000 \mathrm{~g}$ for $10 \mathrm{~min}$ at $4^{\circ} \mathrm{C}$. Cerebral tissue samples were dissected on an ice bed, and all the samples were stored at $-80^{\circ} \mathrm{C}$ until use.

\section{Diets}

Diets used in the study were purchased from SAFE. The rats were allowed to acclimatise and fed the control diet for 3 weeks. The control diet (C; $14633 \mathrm{~kJ} / \mathrm{kg}$ (3495 kcal $/ \mathrm{kg})$ ) contained 5\% cellulose, $20 \%$ casein, 25\% maize starch, $25 \%$ potato starch, $16 \%$ maltodextrin, $4 \%$ soyabean oil, $3.5 \%$ American Institute of Nutrition mineral mix, 1\% American Institute of Nutrition vitamin mix, 0.3\% DL-methionine and $0 \cdot 2 \%$ choline bitartrate. The $\mathrm{HF} / \mathrm{HFr}$ diet was similar to the $\mathrm{C}$ diet, except that maize starch, potato starch and maltodextrin were replaced with $46 \%$ fructose and $20 \%$ lard $(19293 \mathrm{~kJ} / \mathrm{kg}(4608 \mathrm{kcal} / \mathrm{kg}))$. Insulin resistance induced by the HF/HFr diet has been confirmed in a previous study ${ }^{(28)}$.

\section{Experiment 1}

A total of thirty-two male Wistar rats (5 weeks old) were randomly divided into two groups and fed ad libitum for 12 weeks the $\mathrm{C}$ diet or the HF/HFr diet. At the end of the dietary period, half the rats in each group were administered a single intraperitoneal injection of LPS, $100 \mu \mathrm{g} / \mathrm{kg}$ (SigmaAldrich, Escherichia coli serotype 0127:B8). The control rats were treated with saline, and all the injections were administered in the morning (09.00-12.00 hours). The rats were 
killed $8 \mathrm{~h}$ after injection as described by Pohl et al. ${ }^{(11)}$, as this time point corresponds to the peak in the response of cytokines in obese rats after the administration of this dose of LPS.

\section{Experiment 2}

A total of 120 male Wistar rats (5 weeks old) were randomly divided into four groups of thirty and fed ad libitum for 12 weeks one of the following four diets: $\mathrm{C}$ diet, the $\mathrm{HF} / \mathrm{HFr}$ diet, or the respective diets containing $20 \mathrm{~g}$ of $\mathrm{CN}$ per $\mathrm{kg}$ of diet $(\mathrm{C}+\mathrm{CN}$ or $\mathrm{HF} / \mathrm{HFr}+\mathrm{CN})$. The amount of $\mathrm{CN}$ used was based on our previous study showing a definite effect of $20 \mathrm{~g}$ of $\mathrm{CN}$ per $\mathrm{kg}$ of diet in rats ${ }^{(29)}$. The composition of $\mathrm{CN}$ has been described by Couturier et al. ${ }^{(28)}$. The $\mathrm{CN}$ powder (Cinnamomum burmannii) was obtained from McCormick Spice. A water extract of the $\mathrm{CN}$ powder contained more than 5\% type A polyphenols with a tetramer with a molecular weight of 1152 and two trimers with a molecular weight of
$864^{(30,31)}$. From each group, ten rats were exposed to restraint Str in a contention tube for $30 \mathrm{~min}$ just before being killed. The rats were dissected to evaluate their body composition. The livers and two depots of adipose tissue were carefully removed and weighed: mesenteric (along the mesentery, starting from the lesser curvature of the stomach and ending at the sigmoid colon) and inguinal (subcutaneous fat between the lower part of the rib cage and the thighs).

\section{Measurement of plasma concentrations of cytokines}

The plasma concentrations of IL- $1 \beta$, IL- 6 , TNF- $\alpha$, IL- 2 and IL-10 were measured using a rat cytokine LINCOplex 5-plex kit (Linco research, Inc.) on a Bioplex-200 apparatus (BioRad) following the manufacturer's instructions as described previously $^{(32)}$. The intra-assay $\mathrm{CV}$ were $4,4,5,4$ and $4 \%$ and inter-assay $\mathrm{CV}$ were $2,3,7,3$ and $6 \%$, respectively, for IL-1 $\beta$, IL-6, TNF- $\alpha$, IL-2 and IL-10.
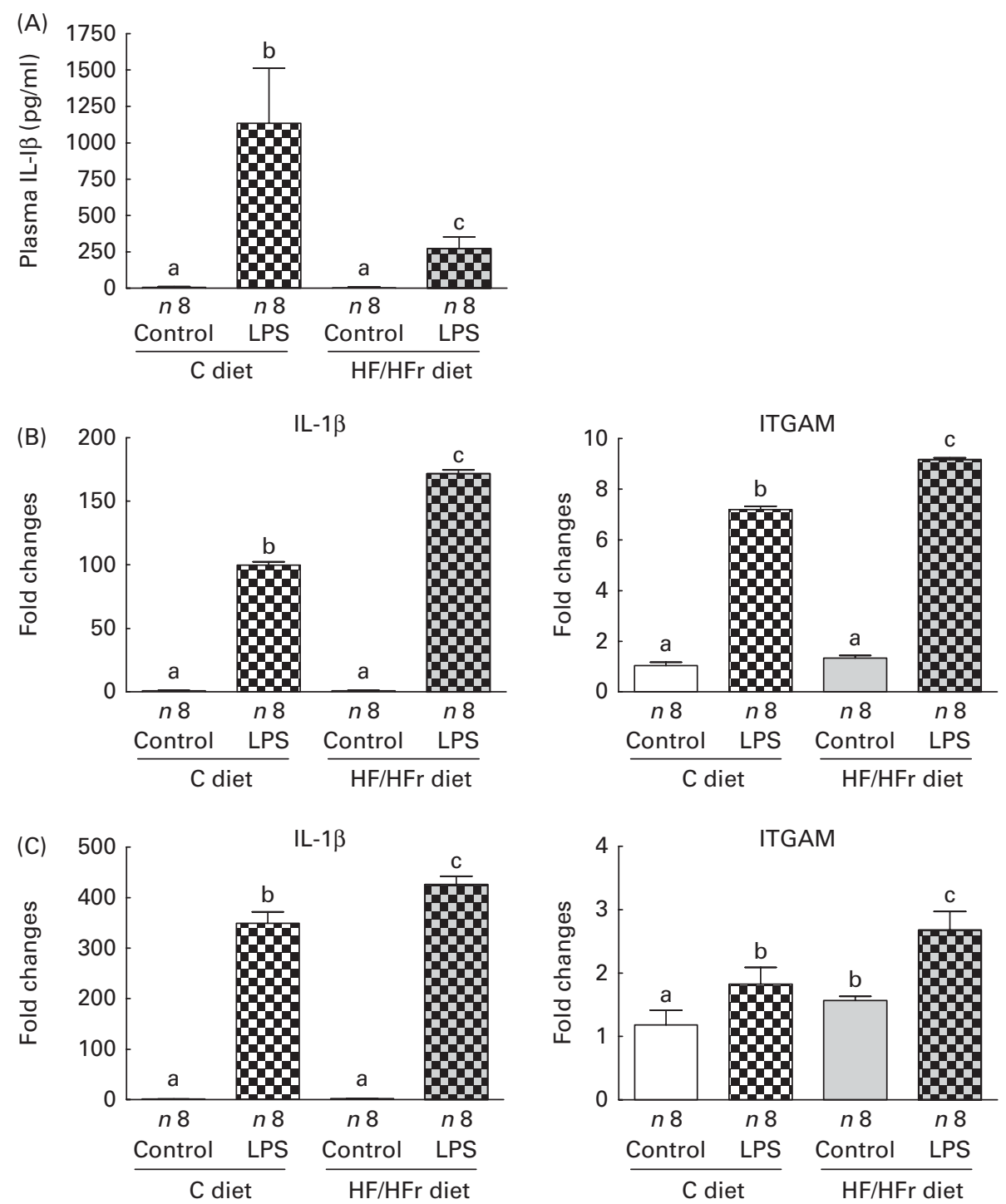

Fig. 1. Effect of lipopolysaccharide (LPS) under the control (C) diet or the high-fat/high-fructose (HF/HFr) diet on the plasma concentrations of (A) IL-1 $\beta$ and (B) hypothalamic and (C) hippocampal expression of IL-1 $\beta$ and integrin- $\alpha$ M (ITGAM). ${ }^{a, b, c}$ Values with unlike letters were significantly different $(P<0.05)$. 
The concentrations of plasma corticosterone were measured with an in-house RIA ${ }^{(33)}$ using a highly specific antibody provided by H. Vaudry (University of Rouen, France). Briefly, after the extraction of steroids from plasma samples with absolute ethanol, we measured the concentrations of total corticosterone by competition between cold corticosterone and ${ }^{3} \mathrm{H}$-corticosterone using our specific antibody anti-corticosterone.

\section{Measurement of the central expression of genes}

The expression levels of mRNA were measured by real-time RT PCR using SYBR ${ }^{\circledR}$ Green I (Life Technologies) as the fluorescent marker ${ }^{(34)}$. Total RNA was extracted from the hypothalamus and hippocampus using a TRIzol ${ }^{\circledR}$ extraction kit (Invitrogen) according to the manufacturer's instructions. Samples in a final volume of $30 \mu$ l were treated with DNAse (Turbo DNA-free Kit, Ambion, Invitrogen). RNA were quantified on the NanoDrop 1000 (Thermo Scientific), and their quality was estimated on Agilent RNA 6000 nano chips using the Agilent 2100 Bioanalyzer (Agilent Technologies). RT were carried out using aliquots of total RNA $(2 \mu \mathrm{g})$ using a Superscript III Invitrogen kit (Invitrogen, Life Technologies). The RT reactions were carried out in $20 \mu \mathrm{l}$ of reaction buffer at $50^{\circ} \mathrm{C}$ for $55 \mathrm{~min}$ and terminated by heating at $85^{\circ} \mathrm{C}$ for 5 min followed by cooling at $4^{\circ} \mathrm{C}$. The primers were designed using the Primer Express ${ }^{\circledR}$ program (Applied Biosystems). We measured the hypothalamic and hippocampal expression of immune factors (IL-1 $\beta$, IL-1 receptor antagonist, IL- 1 receptor (IL-1R)1, IL-6, IL-6R, glycoprotein 130 (Gp130), TNF- $\alpha$, TNF receptor (TNF-R)1, TNF-R2, NF-кB, inhibitor of $\kappa \mathrm{B}$, cyclooxygenase 2 (COX2), integrin- $\alpha M$ (ITGAM) (or Cdllb), transforming growth factor (TGF)- $\beta 1$, TGF- $\beta 2$, TGF- $\beta$ receptor 1 and TGF- $\beta$ receptor 2), actors of HPA axis function (corticotrophin-releasing hormone, MR, GR, 11 $\beta$-HSD1 and $11 \beta-H S D 2$ ) and actors of cerebral plasticity (neurogenesis with brain-dervied neurotrophic factor (BDNF) and its receptor tyrosine kinase receptor (TrK) B and nerve growth factor (NGF) and its receptor TrkA and synaptogenesis with synaptophysin (SYP), synaptotagmin, neurogranin, growth-associated protein 43 (GAP43) and discs, large (Drosophila) homologassociated protein 2 (DlGap2). The sequences of primers used and the description of the abbreviations are given in Table S1 (available online). We tested the primers by quantitative PCR (qPCR) with a standard curve of concentrations obtained with a pool of our complementary DNA to evaluate their efficacy (which should be between 95 and 105\%) and specificity. We also tested them on agarose gel for their ability to produce a single product of correct size. Each sample of complementary DNA was randomly measured in duplicates of $4 \mathrm{ng}$ for the target and housekeeping genes. Real-time PCR were carried out in ninety-six-well plates with the Opticon 2 BioRad Software (MJ Research) using the DynamoTM HS SYBR ${ }^{\circledR}$ Green qPCR Kit Finnzymes (Ozyme). The reactions were carried out at $95^{\circ} \mathrm{C}$ for $15 \mathrm{~min}$, followed by forty cycles of $95^{\circ} \mathrm{C}$ for $20 \mathrm{~s}$ and $61^{\circ} \mathrm{C}$ for $35 \mathrm{~s}$. The fluorescence of the SYBR Green dye was determined as a function of the PCR cycle 

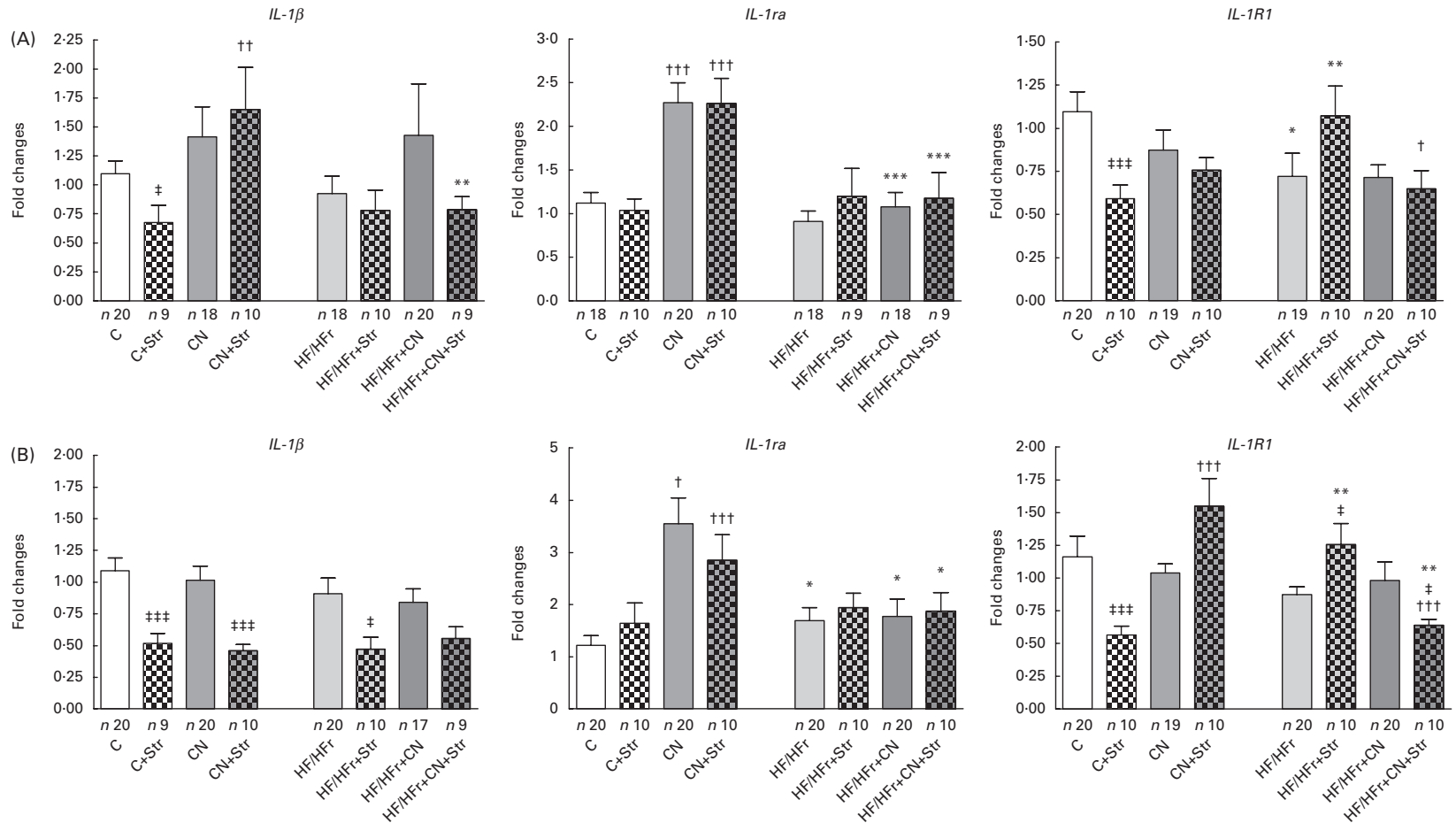

Fig. 2. (A) Hypothalamic and (B) hippocampal expression of pro-inflammatory cytokine IL-1 3 , its antagonist IL-1 receptor antagonist (IL-1ra) and IL-1 receptor 1 (IL-1R1) according to the diet (control (C) v. high-fat/high-fructose (HF/HFr)), the cinnamon (CN) supplementation or the stress (Str) condition. The relative expression level of the target gene (fold change) is expressed as $2^{-\Delta \Delta C_{t}}$, when compared with the mean $\Delta C_{t}$ (threshold cycle) of the control group. Values are means, with their standard errors represented by vertical bars. Diet effect, with reference to its control: ${ }^{\star} P<0.05,{ }^{\star \star} P<0.01$, ${ }^{\star \star \star} P<0.001$. Cinnamon effect, with

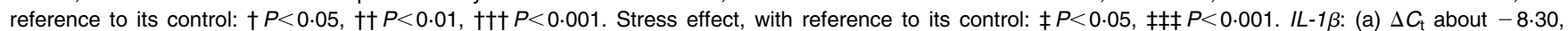
(b) $\Delta C_{\mathrm{t}}$ about -9.82; IL-1ra: (a) $\Delta C_{\mathrm{t}}$ about -9.17, (b) $\Delta C_{\mathrm{t}}$ about -10.28; IL-1R1: (a) $\Delta C_{\mathrm{t}}$ about -3.51 , (b) $\Delta C_{\mathrm{t}}$ about -6.33 .

number, giving the threshold cycle $\left(C_{\mathrm{t}}\right)$ number at which the amplification reached a significant threshold. The $C_{\mathrm{t}}$ values were used to estimate the amount of PCR products according to the $C_{\mathrm{t}}$ of the housekeeping gene. $\Delta C_{\mathrm{t}}$ was calculated by subtracting the $C_{\mathrm{t}}$ of the control gene (enolase 2) from the $C_{\mathrm{t}}$ of the target gene, and the expression level of the target gene was calculated by considering the $C_{\mathrm{t}}$ of enolase 2 to be about 24.06 cycles. The relative expression level of the target gene was expressed as $2^{-\Delta \Delta C_{\mathrm{t}}}$, when compared with the mean $\Delta C_{\mathrm{t}}$ of the control group. The $\Delta C_{\mathrm{t}}$ values were compared using ANOVA (three-way: diet, $\mathrm{CN}$ and Str) and were considered significant when $P<0 \cdot 05$. The expression levels are reported as $2^{-\Delta \Delta C_{\mathrm{t}}}$ (fold change, means with their standard errors).

\section{Statistical analysis}

Results are expressed as means with their standard errors. For experiment 1 , data were analysed by a two-way ANOVA (diets and LPS treatment). For experiment 2, data were first analysed by a three-way ANOVA with diets (C $v$. HF/HFr), with or without $\mathrm{CN}$, and with $\operatorname{Str} v$. no Str. Subsequently, when the results of the three-way ANOVA was significant, given the number of experimental groups, two-way ANOVA were carried out separately for the $\mathrm{C}$ and $\mathrm{HF} / \mathrm{HFr}$ diets. Newman-Keuls post hoc analyses were conducted when the results of the ANOVA were significant $(P<0 \cdot 05)$. They focused on (1) the diet effect upon the inflammation status and the HPA axis, (2) the Str effect and (3) the CN effect.

\section{Results}

\section{Inflammation status}

Experiment 1. The plasma concentrations of IL-1 $\beta$ increased in response to the LPS treatment (Fig. 1(A)), but to a lesser extent under the HF/HFr diet than under the $\mathrm{C}$ diet (significant diet $\times$ treatment interaction $P<0.05$ ). The same pattern of increase in response to the LPS treatment was observed for the plasma concentrations of IL- 6 , TNF- $\alpha$ and IL-10 according to the diet (Table S2, available online).

Fig. 1(B) and (C) shows the results for the expression of IL-1 $\beta$ and ITGAM in the hypothalamus and hippocampus, respectively, in response to the $\mathrm{HF} / \mathrm{HFr}$ diet and/or LPS treatment. The LPS treatment induced a strong increase in the expression of IL-1 $\beta$ and ITGAM in the hypothalamus (treatment effect $P<0.001)$. This effect was less remarkable for the expression of ITGAM in the hippocampus. In both the structures, the LPS treatment induced a greater increase in the expression of IL-1 $\beta$ under the $\mathrm{HF} / \mathrm{HFr}$ diet than under the $\mathrm{C}$ diet (diet $\times$ treatment interaction $P<0.05$ ). The same results were obtained for the expression of IL- 6 and TNF- $\alpha$ (Table S2, available online).

Experiment 2. Among the cytokines, the plasma concentrations of only IL-6 were increased by the HF/HFr diet 

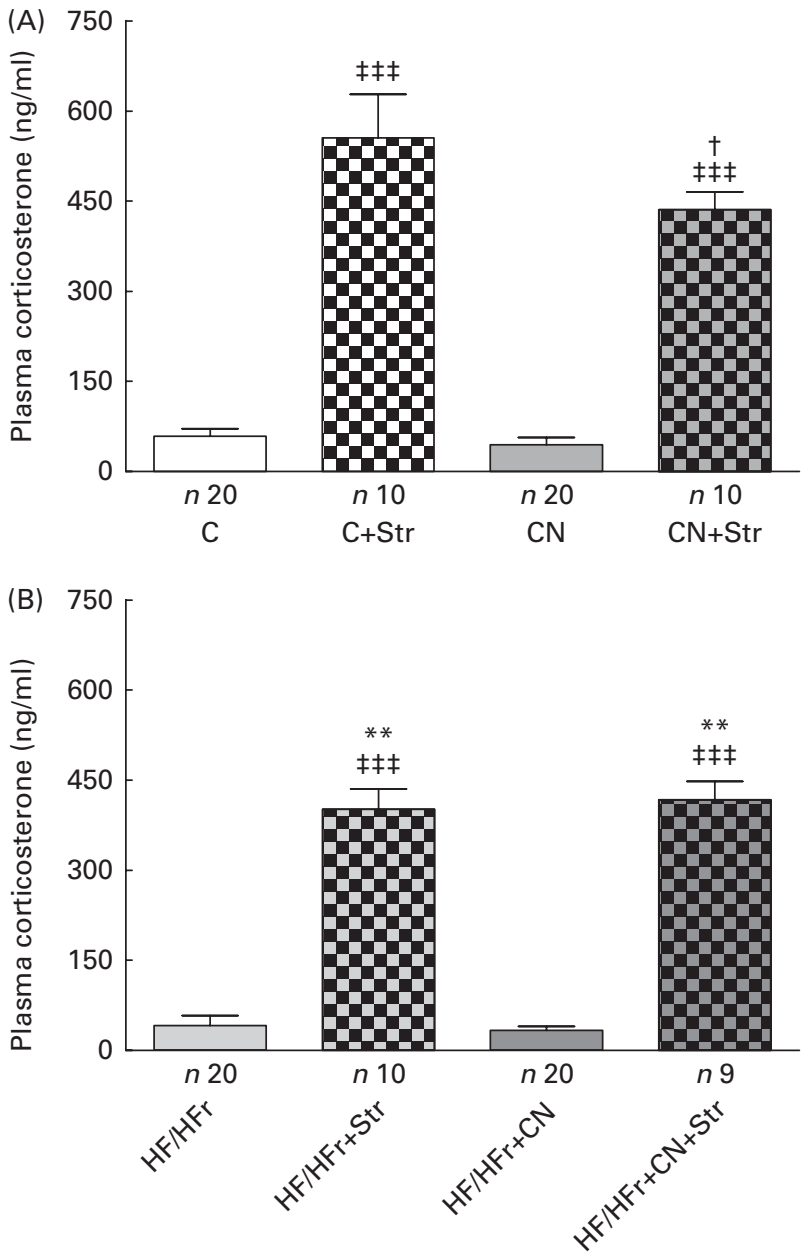

Fig. 3. Post-stress plasma concentrations of corticosterone according to the diet ((A) control (C) $v$. (B) high-fat/high-fructose (HF/HFr)), the cinnamon (CN) supplementation or the stress (Str) condition. Values are means, with their standard errors represented by vertical bars. ${ }^{* *}$ Diet effect, with reference to its control $(P<0.01)$. † Cinnamon effect, with reference to its control $(P<0.05)$. $¥ \ddagger \ddagger$ Stress effect, with reference to its control $(P<0.001)$.

$(P<0 \cdot 05)$, and this effect was reversed by $\mathrm{CN}$ supplementation (Table 1)

The body composition of the rats is summarised in Table S3 (available online). No significant effect was revealed by ANOVA for body weight or fat weight. A strong diet effect was revealed by ANOVA for liver weight. The HF/HFr diet globally increased the liver weight of the rats $(P<0 \cdot 001)$.

Fig. 2 and Tables S4 and S5 (available online) show the main results for the expression of cytokines in the hypothalamus and hippocampus. Results are reported only when ANOVA revealed at least a diet $\times \mathrm{CN} \times \mathrm{Str}$ interaction $(P<0.05)$. Under the $\mathrm{C}$ diet, restraint Str decreased the expression of IL-1 $\beta$, IL-1R1, IL-6 and Gp130 in the hypothalamus and hippocampus. Under the $\mathrm{HF} / \mathrm{HFr}$ diet, restraint Str either exerted no effect or induced an increase in the expression of IL-1R1, IL- 6 and Gp130 in both the structures.

Under the $\mathrm{C}$ diet, $\mathrm{CN}$ supplementation strongly increased the expression of $\mathrm{IL}-1$ receptor antagonist $(P<0.001)$ in the hypothalamus and hippocampus, did not modify (IL-1R1,
IL-6R, TNF- $\alpha$ and receptors) or counteract the effect of Str (IL-1 $\beta$ and IL-6) in the hypothalamus, and did not change (IL-1 $\beta$ ) or counteract the effect of Str (IL-1R1, IL-6, Gp130, TNF- $\alpha$ and TNF-R1) in the hippocampus. Under the HF/HFr diet, $\mathrm{CN}$ supplementation also inhibited the effect of Str on the expression of IL-1R1 and IL- 6 in the hypothalamus and on that of IL-1R1 and IL- 6 and TNF-R1 in the hippocampus.

Results for the expression of intermediates of cytokine transduction, NF- $\kappa \mathrm{B}$, inhibitor of $\kappa \mathrm{B}$, targets such as COX2, ITGAM, and anti-inflammatory factors TGF- $\beta 1$ and TGF- $\beta 2$ and their two receptors in the hypothalamus and hippocampus, are given in Tables S6 and S7 (available online).
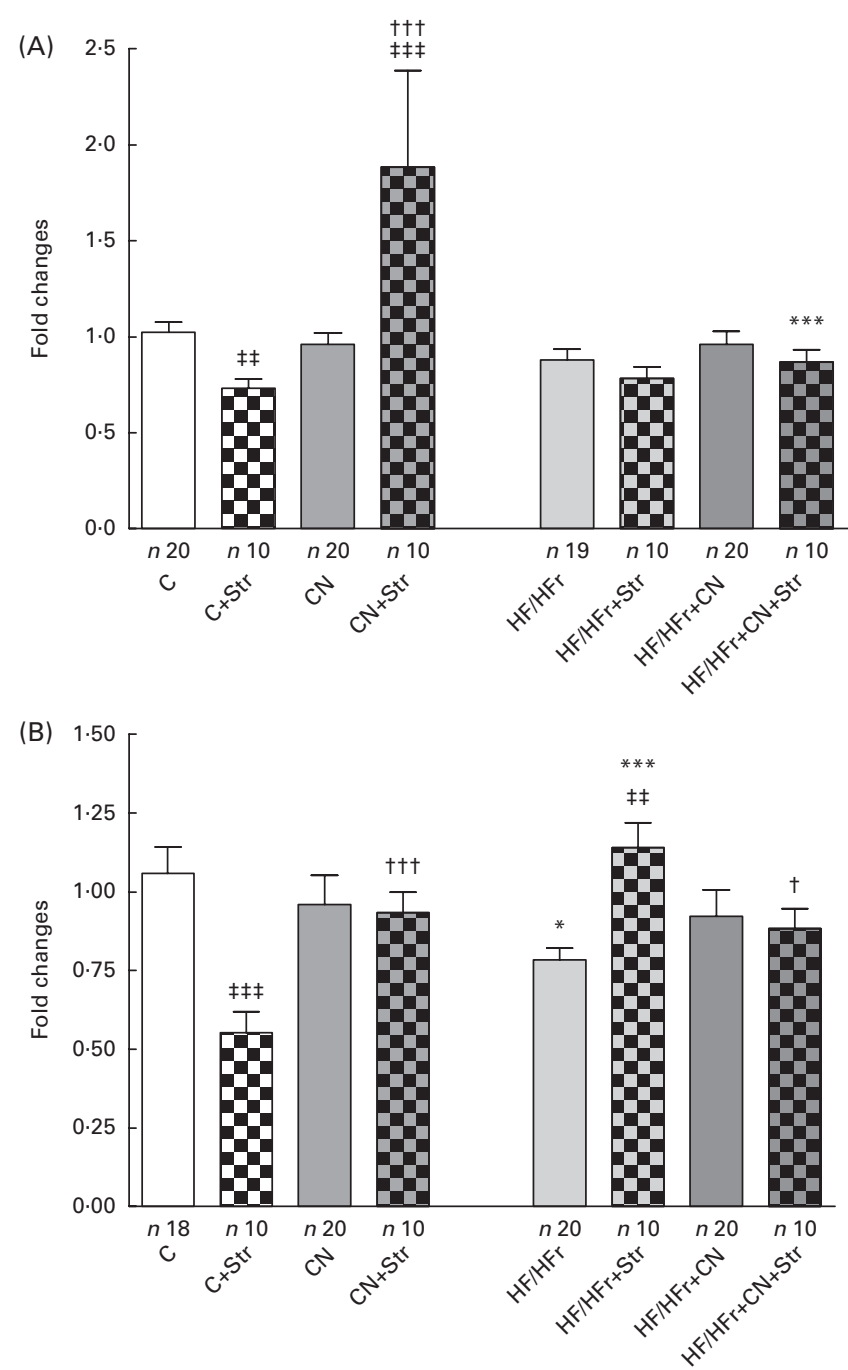

Fig. 4. (A) Hypothalamic and (B) hippocampal expression of the glucocorticoid receptor according to the diet (control (C) $v$. high-fat/high-fructose $(\mathrm{HF} / \mathrm{HFr})$ ), the cinnamon (CN) supplementation or the stress (Str) condition. The relative expression level of the target gene (fold change) is expressed as $2^{-\Delta \Delta C_{t}}$, when compared with the mean $\Delta C_{t}$ (threshold cycle) of the control group. Values are means, with their standard errors represented by vertical bars. Diet effect, with reference to its control: ${ }^{*} P<0.05$, ${ }^{* * *} P<0.001$. Cinnamon effect, with reference to its control: $\dagger P<0.05$, $+\dagger \dagger P<0.001$. Stress

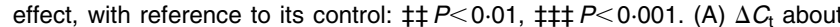
-1.81 ; (B) $\Delta C_{\mathrm{t}}$ about -1.49 . 
Table 2. Hypothalamic expression of the mineralocorticoid receptor and corticotrophin-releasing hormone according to the diet (control (C) v. high-fat/high-fructose (HF/HFr)), the cinnamon (CN) supplementation or the stress (Str) condition§

(Mean values with their standard errors)

\begin{tabular}{|c|c|c|c|c|c|c|c|c|c|c|c|c|c|c|c|c|c|c|c|c|c|c|c|c|}
\hline \multirow{2}{*}{$\begin{array}{l}\text { HPA } \\
\text { actors }\end{array}$} & \multicolumn{3}{|c|}{$\mathrm{C}$} & \multicolumn{3}{|c|}{$\mathrm{C}+\mathrm{Str}$} & \multicolumn{3}{|c|}{$\mathrm{CN}$} & \multicolumn{3}{|c|}{$\mathrm{CN}+\mathrm{Str}$} & \multicolumn{3}{|c|}{$\mathrm{HF} / \mathrm{HFr}$} & \multicolumn{3}{|c|}{$\mathrm{HF} / \mathrm{HFr}+\mathrm{Str}$} & \multicolumn{3}{|c|}{$\mathrm{HF} / \mathrm{HFr}+\mathrm{CN}$} & \multicolumn{3}{|c|}{$\mathrm{HF} / \mathrm{HFr}+\mathrm{CN}+\mathrm{Str}$} \\
\hline & $n$ & Mean & SE & $n$ & Mean & SE & $n$ & Mean & SE & $n$ & Mean & SE & $n$ & Mean & SE & $n$ & Mean & SE & $n$ & Mean & SE & $n$ & Mean & SE \\
\hline MR & 20 & 1.13 & 0.15 & 10 & $0.73 \ddagger$ & 0.05 & 20 & 0.9 & 0.11 & 10 & $1 \cdot 18 \dagger$ & 0.20 & 10 & $0 \cdot 70^{\star \star}$ & 0.07 & 10 & 0.7 & 0.06 & 20 & 0.8 & 0.08 & 10 & $0.62^{\star *}$ & 0.06 \\
\hline $\mathrm{CRH}$ & 20 & 1.05 & 0.08 & 10 & $0.66 \neq \ddagger \ddagger$ & 0.05 & 20 & $0.83 \dagger$ & 0.06 & 10 & 0.81 & 0.11 & 19 & $0.78^{*}$ & 0.05 & 9 & 0.80 & 0.07 & 19 & 0.98 & $0 \cdot 10$ & 10 & 0.77 & $0 \cdot 10$ \\
\hline
\end{tabular}

HPA, hypothalamic-pituitary-adrenocortical axis; $M R$, mineralocorticoid receptors; $C R H$, corticotrophin-releasing hormone

Diet effect, with reference to its control: * $P<0.05,{ }^{* *} P<0.01$.

Cinnamon effect, with reference to its control: $† P<0.05$.

Stress effect, with reference to its control: 执P<0.01; 㧊 $P<0.001$.

$\S$ The relative expression level of the target gene (fold change) is expressed as $2^{-\Delta \Delta C_{\mathrm{t}}}$, when compared with the mean $\Delta C_{\mathrm{t}}$ of the control group.

Table 3. Hippocampal expression of the mineralocorticoid receptor according to the diet (control (C) v. high-fat/high-fructose (HF/HFr)), the cinnamon (CN) supplementation or the stress (Str) condition§

(Mean values with their standard errors)

\begin{tabular}{|c|c|c|c|c|c|c|c|c|c|c|c|c|c|c|c|c|c|c|c|c|c|c|c|c|}
\hline & \multicolumn{3}{|c|}{ C } & \multicolumn{3}{|c|}{$\mathrm{C}+\mathrm{Str}$} & \multicolumn{3}{|c|}{$\mathrm{CN}$} & \multicolumn{3}{|c|}{$\mathrm{CN}+\mathrm{Str}$} & \multicolumn{3}{|c|}{$\mathrm{HF} / \mathrm{HFr}$} & \multicolumn{3}{|c|}{$\mathrm{HF} / \mathrm{HFr}+\mathrm{Str}$} & \multicolumn{3}{|c|}{$\mathrm{HF} / \mathrm{HFr}+\mathrm{CN}$} & \multicolumn{3}{|c|}{$\mathrm{HF} / \mathrm{HFr}+\mathrm{CN}+\mathrm{Str}$} \\
\hline & $n$ & Mean & $\mathrm{SE}$ & $n$ & Mean & SE & $n$ & Mean & SE & $n$ & Mean & SE & $n$ & Mean & SE & $n$ & Mean & $\mathrm{SE}$ & $n$ & Mean & $\mathrm{SE}$ & $n$ & Mean & SE \\
\hline$M R$ & 20 & 1.04 & 0.07 & 10 & $0.78 \ddagger \ddagger$ & 0.08 & 20 & 1.04 & 0.05 & 10 & $1.09 \dagger \dagger$ & 0.07 & 20 & 1.08 & 0.05 & 10 & $1 \cdot 12^{\star \star}$ & 0.07 & 20 & 1.03 & 0.06 & 10 & 1.02 & 0.09 \\
\hline
\end{tabular}

$M R$, mineralocorticoid receptors

Diet effect, with reference to its control: $* * P<0.01$

Cinnamon effect with reference to its control: $++P<0.01$.

Stress effect, with reference to its control: $+t+P<0.001$.

$\S$ The relative expression level of the target gene (fold change) is expressed as $2^{-\Delta \Delta C_{t}}$, when compared with the mean $\Delta C_{t}$ of the control group. 


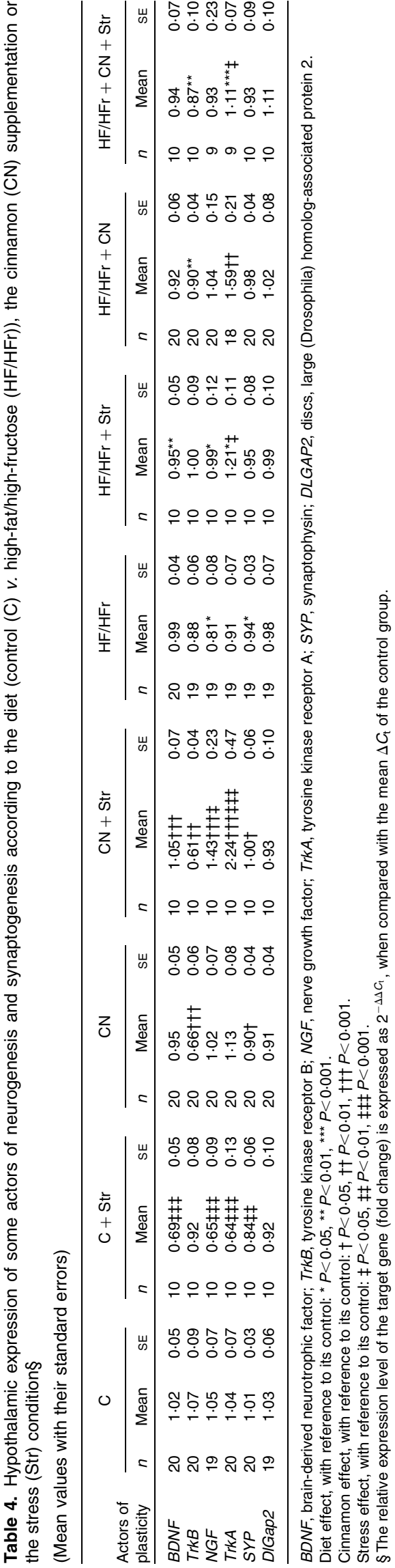

\section{Hypothalamic-pituitary-adrenocortical axis function}

A strong Str effect $(P<0 \cdot 001)$, a diet effect $(P<0 \cdot 01)$, and $\operatorname{diet} \times \mathrm{CN}$ and $\operatorname{diet} \times$ Str interactions $(P<0.05)$ were revealed by ANOVA for the plasma concentrations of corticosterone. Str strongly increased the plasma concentrations of corticosterone under the $\mathrm{C}$ diet than under the HF/HFr diet $(P<0 \cdot 01$; Fig. 3) or CN supplementation $(P<0 \cdot 05)$.

A Str effect was revealed by ANOVA for the expression of genes related to HPA axis function in the central structures $(P<0 \cdot 05)$. Under the $\mathrm{C}$ diet, Str induced a decrease in the hypothalamic expression of corticotrophin-releasing hormone and in the hypothalamic and hippocampal expression of MR and GR (Fig. 4; Tables 2 and 3). Under the HF/HFr diet, Str either exerted no effect or induced an increase in $(G R)$ mRNA levels. CN supplementation reduced or suppressed the effects of Str irrespective of the diet. Results for the hypothalamic and hippocampal expression of $11 \beta-H S D 1$ and $11 \beta-H S D 2$ are shown in Fig. S8 (available online).

\section{Cerebral plasticity}

Neurogenesis. A Str effect $(P<0.05)$ and a Str $\times \mathrm{CN}$ interaction $(P<0.05)$ were revealed by ANOVA for the expression of BDNF and NGF under the $\mathrm{C}$ diet in both the hypothalamus and hippocampus. A profile the same as that for immune factors and HPA axis function was observed for BDNF and NGF, as shown in Tables 4 and 5, i.e. under the $\mathrm{C}$ diet, a decrease in the expression induced by Str and an inhibition of this effect by $\mathrm{CN}$ supplementation in both the hypothalamus and hippocampus. The $\mathrm{HF} / \mathrm{HFr}$ diet once again reversed or blunted these effects (diet $\times$ CN interaction $P<0 \cdot 05$ ).

Synaptogenesis. The most interesting results were obtained for the hippocampal expression of SYP and DlGap2 (Fig. 5; other data given in Tables S9 and S10 (available online)). A diet effect $(P<0.01)$ was revealed by ANOVA for the expression of SYP in the hippocampus and a diet $\times \mathrm{CN} \times$ Str interaction $(P<0.01)$ was revealed for the expression of SYP in the hypothalamus and hippocampus and for that of DlGap2 in the hippocampus. The histograms showed a profile the same as those described above: a decrease in the expression by Str under the $\mathrm{C}$ diet and a reversion of this effect by the HF/HFr diet. CN supplementation counteracted the effect of Str, irrespective of the diet.

\section{Discussion}

The present study aimed to determine the effects of a HF/HFr diet, restraint Str and/or dietary $\mathrm{CN}$ supplementation on plasma cytokines and corticosterone and hypothalamic and hippocampal expression of actors of immune function, HPA axis function and cerebral plasticity. Protein data would also be very interesting in this context, but considering the low levels of variations expected, we chose to quantitatively determine the variations in the expression of genes by qPCR.

A low-level inflammatory state is usually associated with visceral obesity ${ }^{(35)}$, but is still controversial and not reproducible in rodents. In the present study, only plasma 
concentrations of IL- 6 were increased significantly by the $\mathrm{HF} / \mathrm{HFr}$ diet. The plasma concentrations or central expression of other cytokines was not modified by the high-energy diet, perhaps due to there being no enough fat to induce such a reaction ${ }^{(11,36,37)}$. We studied the response of Wistar rats to a challenge with LPS at a moderate dose, as has been already done earlier in this context ${ }^{(11)}$. Indeed, a recent study has shown a sensitisation of the plasma concentrations and hypothalamic expression of pro-inflammatory cytokines in rats subjected to LPS treatment at the same dose ${ }^{(11)}$. In the present study, the plasma concentrations of cytokines were less increased by the LPS treatment under the HF/HFr diet than under the $\mathrm{C}$ diet. On the other hand, a stronger response of the hypothalamus and hippocampus to the LPS treatment was observed, inflammatory message perhaps due to an increase in the levels of between the periphery and the cerebral structures in $\mathrm{HF} / \mathrm{HFr}$ rats. For the inflammatory state in the periphery, we did not obtain results the same as those reported by Pohl et al. ${ }^{(11)}$; that is, we found no increase, perhaps because of a different diet or a higher body weight of the obese rats in their study. However, in agreement with the findings of their study, we observed an induction of the central inflammatory state. In case of obesity, such a hypersensitisation of the hypothalamic and hippocampal inflammatory processes could have, in the long term, a deleterious effect on normal cognitive functions ${ }^{(10)}$.

Str did not alter the plasma concentrations of cytokines, whereas it decreased the central expression of IL-1 and its receptor, IL- 6 and TNF- $\alpha$. Globally, central cytokines seem to be more sensitive to environmental challenges than peripheral cytokines. The HF/HFr diet abolished or even reversed this effect of Str. Such an effect of a high-energy diet illustrates the comfort food theory ${ }^{(38)}$, but at the molecular level. According to this theory, a high-fat diet would act directly on the brain and by an intermediate process, which could, for instance, arise from the visceral fat, to counteract the effect of Str.

The HF/HFr diet that we used did not contain enough fat to induce visceral obesity, but it induced fatty livers and insulin resistance as has been shown previously ${ }^{(28)}$. Str strongly increased the plasma concentrations of corticosterone, but in each group, Str increased the plasma concentrations of corticosterone to a lesser extent under the HF/HFr diet than under the $\mathrm{C}$ diet. This is also in line with the comfort food theory and a lower effect of Str under a high-energy diet. The HF/HFr diet did not affect the central expression of HPA components in standard conditions. Str strongly decreased the central expression of MR and GR in rats fed the $\mathrm{C}$ diet, in agreement with the classical autoregulation of corticosteroid receptors ${ }^{(39)}$. Once again, this effect was either blunted or reversed by the $\mathrm{HF} / \mathrm{HFr}$ diet.

Under the $\mathrm{C}$ diet, the expression of actors of neurogenesis and synaptogenesis was decreased by Str, which corresponds to the classical deleterious effect of glucocorticoids at a high dose at the central level ${ }^{(15,40)}$. Under the HF/HFr diet, this effect was reversed for the expression of SYP and DlGap2. In this case, the $\mathrm{HF} / \mathrm{HFr}$ diet could be protective against the central effects of Str, in accordance with the comfort food theory. The modulation of the effect of glucocorticoids by 

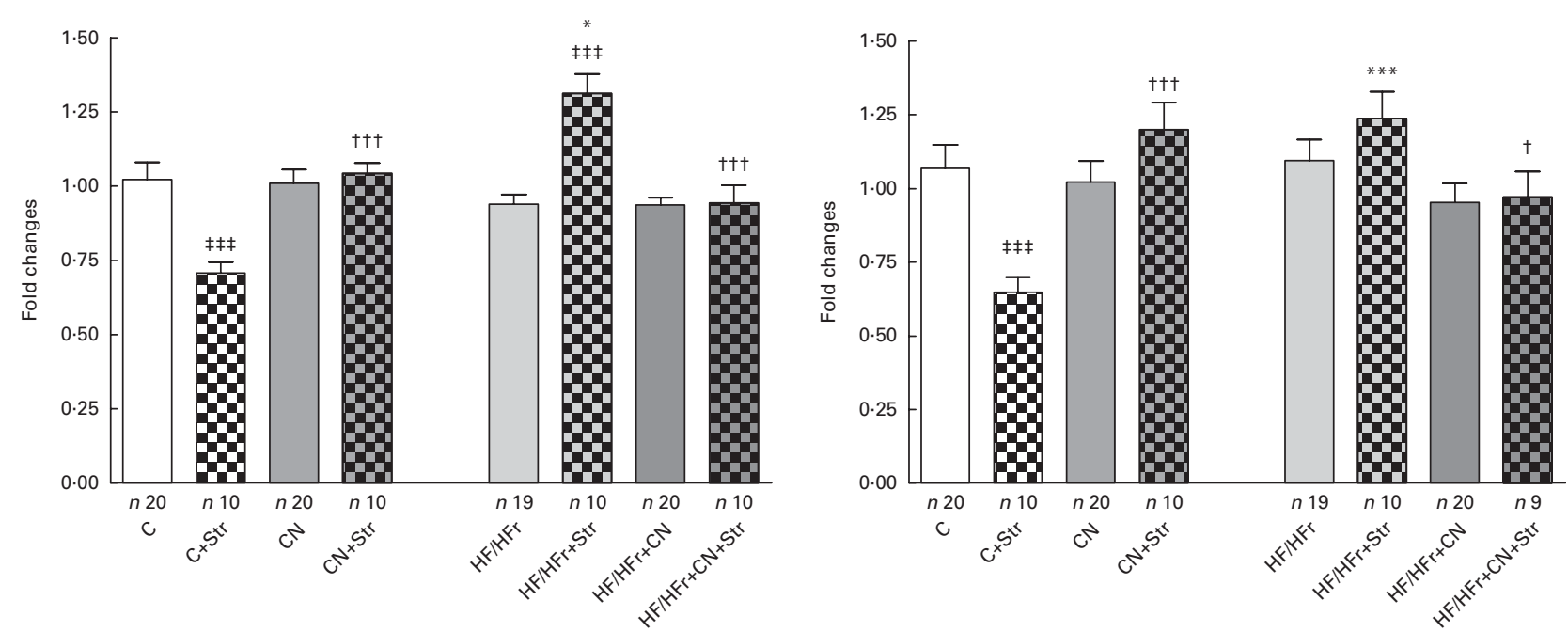

Fig. 5. Hippocampal expression of some actors of synaptogenesis according to the diet (control (C) $v$. high-fat/high-fructose (HF/HFr)), the cinnamon (CN) supplementation or the stress (Str) condition. (A) Synaptophysin, (B) discs, large (Drosophila) homolog-associated protein 2 (DIGap2). The relative expression level of the target gene (fold change) is expressed as $2^{-\Delta \Delta C_{\mathrm{t}}}$, when compared with the mean $\Delta C_{\mathrm{t}}$ (threshold cycle) of the control group. Values are means, with their standard errors represented by vertical bars. Diet effect, with reference to its control: ${ }^{\star} P<0.05,{ }^{\star \star \star} P<0.001$. Cinnamon effect, with reference to its control: $\dagger P<0.05, \dagger_{\dagger} P<0.001$. ¥¥¥ Stress effect, with reference to its control $(P<0.001)$. (A) $\Delta C_{\mathrm{t}}$ about 2.19; (B) $\Delta C_{\mathrm{t}}$ about -1.11 .

the composition of a diet could involve numerous factors of the cellular machinery and needs to be investigated further.

$\mathrm{CN}$ exerted different effects according to the diet. CN has been described to exert numerous beneficial effects under a standard diet ${ }^{(26)}$. The active components of $\mathrm{CN}$ have been known to exert several pharmacological effects such as anti-inflammatory, antioxidant, anti-tumour, anti-obesity and anti-diabetic effects. We confirmed its anti-inflammatory actions in some cases. For instance, the plasma concentrations of IL-6 that were increased by the HF/HF diet were restored to basal levels by $\mathrm{CN}$ supplementation. In both the hypothalamus and hippocampus, under the $\mathrm{C}$ diet, $\mathrm{CN}$ supplementation increased the expression of IL-1 receptor antagonist, an antagonist of IL-1 $\beta$, which could contribute to the beneficial anti-inflammatory and antioxidant effects of $\mathrm{CN}$. On the other hand, this effect was not observed under the HF/HFr diet. Along this line of discussion, it is worth noting that the beneficial effects of $\mathrm{CN}$ under a control diet disappear under an unbalanced diet.

Under the $\mathrm{C}$ diet, $\mathrm{CN}$ supplementation decreased the response of plasma corticosterone to restraint Str. Under this diet, Str decreased the expression of numerous factors involved in immune system, HPA axis function or cerebral plasticity, and this effect was reversed by $\mathrm{CN}$ supplementation. Under the $\mathrm{HF} / \mathrm{HFr}$ diet, the effect of $\mathrm{CN}$ supplementation on plasma corticosterone and central GR expression in response to Str disappeared. Perhaps, there exists an interaction between compounds of the $\mathrm{HF} / \mathrm{HFr}$ diet and $\mathrm{CN}$ to blunt this effect. The HF/HFr diet either blunted or reversed the effects of both Str and CN supplementation. In the case of actors of cerebral plasticity, the effect of $\mathrm{CN}$ supplementation in reversing the Str-induced increase of the expression of SYP and DlGap2 under the HF/HFr diet could be seen as deleterious.

Co-activators and co-repressors are integral components of the signal transduction pathways of steroid hormones.
GR enhances or represses the transcription of target genes by directly binding to the glucocorticoid responsive element, by interacting with other transcription factors apart from binding to DNA or, in a composite manner, by both directly binding to glucocorticoid responsive element and interacting with other transcription factors bound to neighbouring sites ${ }^{(41)}$. The c-AMP response element-binding protein (CREB)-binding protein could be a good candidate for the effect of $\mathrm{CN}$ or diet on GR action, because it may function not only as a co-activator but also as a repressor, depending on the local concentration of other co-activators $^{(42)}$. Nevertheless, no interaction between CREB-binding protein and polyphenols has been described in the literature so far. On the other hand, recent data suggest that polyphenols can function as modifiers of signal transduction pathways to exert their beneficial effects, mainly by acting through NF- $\mathrm{B}$, activator protein 1 (AP-1) and mitogenactivated protein kinases signalling, which also interacts with $\mathrm{GR}^{(43,44)}$. The explorations of the actions of $\mathrm{CN}$ on cellular machinery are still limited. $\mathrm{CN}$ extract has recently been shown to inhibit the activation of p38, c-Jun N-terminal kinase, extracellular-signal-regulated kinase $1 / 2$ and signal transducer and activator of transcription 4 in vitro ${ }^{(45)}$. CN extract induces tumour cell death through the inhibition of NF- $\mathrm{B}$, via three signal transduction pathways, NF-кB-inducing kinase/ІкB kinase (NIK/IKK), extracellular-signal-regulated kinase and p38 mitogen-activated protein kinases ${ }^{(46)}$, and through AP- ${ }^{(47)}$. Another means to change GR transactivation and signalling would be its phosphorylation state ${ }^{(41)}$. CN has recently been found to inhibit PKA activity in vitro ${ }^{(48)}$. Cinnamaldehyde, a major active component of $\mathrm{CN}$, has also recently been shown to increase the phosphorylation levels of the insulin-like growth factor-1 receptor and its downstream signalling molecules ${ }^{(49)}$. 


\section{Conclusions}

In conclusion, we showed that in rats fed a HF/HFr diet there is an increase in the plasma concentrations of IL- 6 and that the central structures of their immune system exhibit a high sensitisation to LPS. We also showed that the HF/HFr diet is sufficient to reverse the negative effects of Str on central gene expression. These data confirm the comfort food theory at the molecular level. CN exerted beneficial effects under the $\mathrm{C}$ diet (notably via an increase in the expression of IL-1 receptor antagonist and by counteracting the effects of Str), but its effects were blunted or even reversed under the HF/HFr diet. Numerous processes are candidate to these effects of inversion of Str responses by the diet or by $\mathrm{CN}$, and need to be further investigated.

\section{Supplementary material}

To view supplementary material for this article, please visit http://dx.doi.org/10.1017/S0007114513003577

\section{Acknowledgements}

The authors thank Thierry Leste-Lassere and Guillaume Drutel for their useful advice on qPCR. They thank Nadine Fidier and Renaud Maury for their help during dissections. They also thank Martine Schuler for her careful reading of the manuscript and her corrections of the language of the article.

The present study was supported by the ANR (Agence Nationale de la Recherche) 'CERVIRMIT' project (ANR-07PNRA-003-02). The funders had no role in study design, data collection and analysis, decision to publish, or preparation of the manuscript.

The authors' contributions are as follows: N. M.-A. wrote the manuscript and was responsible for Bioplex and qPCR measurements; C. B., F. C. and L. P. took care of the animals, carried out the LPS challenge test and were responsible for animal killing and dissections; J. D. was involved in mRNA extraction and qPCR measurements; K. C. and I. H.-F. were responsible for animal killing and dissections in experiment 2 ; M.-P. M. was in charge of reading the manuscript; A.-M. R. and P. M. supervised this work.

None of the authors has any conflicts of interest to declare.

\section{References}

1. MohanKumar SM, King A, Shin AC, et al. (2007) Developmental programming of cardiovascular disorders: focus on hypertension. Rev Endocr Metab Disord 8, 115-125.

2. Nikolajczyk BS, Jagannathan-Bogdan M, Shin H, et al. (2011) State of the union between metabolism and the immune system in type 2 diabetes. Genes Immun 12, 239-250.

3. Roberts DL, Dive C \& Renehan AG (2010) Biological mechanisms linking obesity and cancer risk: new perspectives. Annu Rev Med 61, 301-316.

4. Kerwin DR, Gaussoin SA, Chlebowski RT, et al. (2011) Interaction between body mass index and central adiposity and risk of incident cognitive impairment and dementia: results from the Women's Health Initiative Memory Study. J Am Geriatr Soc 59, 107-112.
5. Winocur G \& Greenwood CE (2005) Studies of the effects of high fat diets on cognitive function in a rat model. Neurobiol Aging 26, Suppl. 1, 46-49.

6. Ferder L, Ferder MD \& Inserra F (2010) The role of high-fructose corn syrup in metabolic syndrome and hypertension. Curr Hypertens Rep 12, 105-112.

7. Tappy L (2012) Q\&A: 'toxic' effects of sugar: should we be afraid of fructose? BMC Biol 10, 42.

8. Bastard JP, Maachi M, Lagathu C, et al. (2006) Recent advances in the relationship between obesity, inflammation, and insulin resistance. Eur Cytokine Netw 17, 4-12.

9. Clement K \& Langin D (2007) Regulation of inflammationrelated genes in human adipose tissue. J Intern Med $\mathbf{2 6 2}$, $422-430$.

10. Capuron L \& Miller AH (2011) Immune system to brain signaling: neuropsychopharmacological implications. Pharmacol Ther 130, 226-238.

11. Pohl J, Woodside B \& Luheshi GN (2009) Changes in hypothalamically mediated acute-phase inflammatory responses to lipopolysaccharide in diet-induced obese rats. Endocrinology 150, 4901-4910.

12. Csolle C \& Sperlagh B (2010) Peripheral origin of IL-1beta production in the rodent hippocampus under in vivo systemic bacterial lipopolysaccharide (LPS) challenge and its regulation by P2X(7) receptors. J Neuroimmunol 219, 38-46.

13. Jeon BT, Jeong EA, Shin HJ, et al. (2012) Resveratrol attenuates obesity-associated peripheral and central inflammation and improves memory deficit in mice fed a high-fat diet. Diabetes 61, 1444-1454.

14. McNay DE, Briancon N, Kokoeva MV, et al. (2012) Remodeling of the arcuate nucleus energy-balance circuit is inhibited in obese mice. J Clin Invest 122, 142-152.

15. Oitzl MS, Champagne DL, van der Veen R, et al. (2010) Brain development under stress: hypotheses of glucocorticoid actions revisited. Neurosci Biobehav Rev 34, 853-866.

16. Mormede P, Foury A, Barat P, et al. (2011) Molecular genetics of hypothalamic-pituitary-adrenal axis activity and function. Ann N Y Acad Sci 1220, 127-136.

17. Chrousos GP \& Kino T (2009) Glucocorticoid signaling in the cell. Expanding clinical implications to complex human behavioral and somatic disorders. Ann N Y Acad Sci 1179, 153-166.

18. Draper N \& Stewart PM (2005) 11beta-hydroxysteroid dehydrogenase and the pre-receptor regulation of corticosteroid hormone action. J Endocrinol 186, 251-271.

19. Rosmond R, Dallman MF \& Bjorntorp P (1998) Stress-related cortisol secretion in men: relationships with abdominal obesity and endocrine, metabolic and hemodynamic abnormalities. J Clin Endocrinol Metab 83, 1853-1859.

20. Cano P, Jimenez-Ortega V, Larrad A, et al. (2008) Effect of a high-fat diet on 24-h pattern of circulating levels of prolactin, luteinizing hormone, testosterone, corticosterone, thyroidstimulating hormone and glucose, and pineal melatonin content, in rats. Endocrine 33, 118-125.

21. Marissal-Arvy N, Langlois A, Tridon C, et al. (2011) Functional variability in corticosteroid receptors is a major component of strain differences in fat deposition and metabolic consequences of enriched diets in rat. Metabolism 60, 706-719.

22. Devenport L, Knehans A, Sundstrom A, et al. (1989) Corticosterone's dual metabolic actions. Life Sciences $\mathbf{4 5}$, 1389-1396.

23. Morton NM (2010) Obesity and corticosteroids: 11betahydroxysteroid type 1 as a cause and therapeutic target in metabolic disease. Mol Cell Endocrinol 316, 154-164. 
24. Pace TW, Hu F \& Miller AH (2007) Cytokine-effects on glucocorticoid receptor function: relevance to glucocorticoid resistance and the pathophysiology and treatment of major depression. Brain Behav Immun 21, 9-19.

25. Qin B, Dawson H, Polansky MM, et al. (2009) Cinnamon extract attenuates TNF-alpha-induced intestinal lipoprotein ApoB48 overproduction by regulating inflammatory, insulin, and lipoprotein pathways in enterocytes. Horm Metab Res 41, 516-522.

26. Qin B, Polansky MM \& Anderson RA (2010) Cinnamon extract regulates plasma levels of adipose-derived factors and expression of multiple genes related to carbohydrate metabolism and lipogenesis in adipose tissue of fructosefed rats. Horm Metab Res 42, 187-193.

27. Frydman-Marom A, Levin A, Farfara D, et al. (2011) Orally administrated cinnamon extract reduces beta-amyloid oligomerization and corrects cognitive impairment in Alzheimer's disease animal models. PLOS ONE 6, e16564.

28. Couturier K, Qin B, Batandier C, et al. (2011) Cinnamon increases liver glycogen in an animal model of insulin resistance. Metabolism 60, 1590-1597.

29. Preuss HG, Echard B, Polansky MM, et al. (2006) Whole cinnamon and aqueous extracts ameliorate sucrose-induced blood pressure elevations in spontaneously hypertensive rats. J Am Coll Nutr 25, 144-150.

30. Lu J, Zhang K, Nam S, et al. (2010) Novel angiogenesis inhibitory activity in cinnamon extract blocks VEGFR2 kinase and downstream signaling. Carcinogenesis 31, 481-488.

31. Anderson RA, Broadhurst CL, Polansky MM, et al. (2004) Isolation and characterization of polyphenol type-A polymers from cinnamon with insulin-like biological activity. J Agric Food Chem 52, 65-70.

32. Moreau M, Andre C, O'Connor JC, et al. (2008) Inoculation of Bacillus Calmette-Guerin to mice induces an acute episode of sickness behavior followed by chronic depressive-like behavior. Brain Behav Immun 22, 1087-1095.

33. Richard EM, Helbling JC, Tridon C, et al. (2010) Plasma transcortin influences endocrine and behavioral stress responses in mice. Endocrinology 151, 649-659.

34. Holland PM, Abramson RD, Watson R, et al. (1991) Detection of specific polymerase chain reaction product by utilizing the $5^{\prime}-3^{\prime}$ exonuclease activity of Thermus aquaticus DNA polymerase. Proc Natl Acad Sci U S A 88, 7276-7280.

35. Tordjman J, Guerre-Millo M \& Clement K (2008) Adipose tissue inflammation and liver pathology in human obesity. Diabetes Metab 34, 658-663.
36. Terra X, Pallares V, Ardevol A, et al. (2011) Modulatory effect of grape-seed procyanidins on local and systemic inflammation in diet-induced obesity rats. $J$ Nutr Biochem 22, 380-387.

37. Cano P, Cardinali DP, Rios-Lugo MJ, et al. (2009) Effect of a high-fat diet on 24-hour pattern of circulating adipocytokines in rats. Obesity (Silver Spring) 17, 1866-1871.

38. Dallman MF, Pecoraro NC \& la Fleur SE (2005) Chronic stress and comfort foods: self-medication and abdominal obesity. Brain Behav Immun 19, 275-280.

39. Schmidt TJ \& Meyer AS (1994) Autoregulation of corticosteroid receptors. How, when, where, and why? Receptor 4 229-257.

40. De Kloet ER, Vreugdenhil E, Oitzl MS, et al. (1998) Brain corticosteroid receptor balance in health and disease. Endocr Rev 19, 269-301.

41. Oakley RH \& Cidlowski JA (2011) Cellular processing of the glucocorticoid receptor gene and protein: new mechanisms for generating tissue-specific actions of glucocorticoids. J Biol Chem 286, 3177-3184

42. Kino T, Nordeen SK \& Chrousos GP (1999) Conditional modulation of glucocorticoid receptor activities by CREBbinding protein (CBP) and p300. J Steroid Biochem Mol Biol 70, 15-25.

43. Santangelo C, Vari R, Scazzocchio B, et al. (2007) Polyphenols, intracellular signalling and inflammation. Ann Ist Super Sanita 43, 394-405.

44. Trzeciakiewicz A, Habauzit V \& Horcajada MN (2009) When nutrition interacts with osteoblast function: molecular mechanisms of polyphenols. Nutr Res Rev 22, 68-81.

45. Lee BJ, Kim YJ, Cho DH, et al. (2011) Immunomodulatory effect of water extract of cinnamon on anti-CD3-induced cytokine responses and p38, JNK, ERK1/2, and STAT4 activation. Immunopharmacol Immunotoxicol 33, 714-722.

46. Kim DH, Kim CH, Kim MS, et al. (2007) Suppression of agerelated inflammatory NF-kappaB activation by cinnamaldehyde. Biogerontology 8, 545-554.

47. Kwon HK, Hwang JS, So JS, et al. (2010) Cinnamon extract induces tumor cell death through inhibition of NFkappaB and AP1. BMC Cancer 10, 392.

48. Moskaug JO, Borge GI, Fagervoll AM, et al. (2008) Dietary polyphenols identified as intracellular protein kinase A inhibitors. Eur J Nutr 47, 460-469.

49. Takasao N, Tsuji-Naito K, Ishikura S, et al. (2012) Cinnamon extract promotes type I collagen biosynthesis via activation of IGF-I signaling in human dermal fibroblasts. J Agric Food Chem 60, 1193-1200. 